\title{
CONVERSA SOBRE EDUCAÇÃO COM RAEWYN CONNELL ${ }^{1}$
}

\section{CONVERSATION ON EDUCATION WITH RAEWYN CONNELL}

\section{CONVERSA SOBRE EDUCACIÓN CON RAEWYN CONNELL}

Carmen Lúcia Guimarães de Mattos²

Márcio Rodrigo Vale Caetano ${ }^{3}$

Paula Almeida de Castro ${ }^{4}$

\begin{abstract}
RESUMO
A conversar com Raewyn Connell tever início pela sua trajetória acadêmica a partir do livro Making the Difference: Schools, Families and Social Division (1982), cuja publicação em língua portuguesa ampliou o interesse de pesquisadores em educação pelos estudos de gênero. Dada a amplitude da produção da autora nesta linha de estudos a conversa continua com indagações sobre a importância para escola em lidar com esse tema, assim como sua interconexão com os estudos sobre masculinidades e suas teorizações internacionais e mais particularmente no Hemisfério Sul, visto que Connell, à época estava divulgando o seu livro Southern Theory: The Global Dynamics of Knowledge in Social Science. Discutiu-se as possibilidades teóricas do Sul pelo Sul, o papel da escola na introdução dos temas sobre as ordenações de gênero e finalmente apresenta-se reflexões dos autores sobre seus próprios questionamentos a cerca da obra da autora.
\end{abstract}

PALAVRAS-CHAVE: Educação, Igualdade, Masculinidade, Gênero, Avaliação Etnografia.

\section{ABSTRACT}

The conversation with Raewyn Connell began with her academic trajectory with the book Making the Difference: Schools, Families and Social Division (1982), published in Portuguese, which expanded the interest of researchers in education on gender studies. Given the scope of the author's production in this line of studies the conversation continues with inquiries about the importance of schools in dealing with this subject, as well as its interconnection with the studies on masculinities and their international influence and more particularly in the Southern

Submetido em: 03/05/2019

Aceito em: 04/05/2019

Publicado em: 01/06/2019

${ }^{1}$ Transcrição da entrevista por Nathan Sany - Whitman College, Walla Walla - WA/EUA.

${ }^{2}$ Universidade do Estado do Rio de Janeiro (UERJ) - Brasil. Formação e instituição [Ph.D]. - University of Pennsylvania, USA. E-mail: clgmattos@gmail.com

${ }^{3}$ Universidade Federal do Rio Grande - FURG \& Bolsista PNPD no Proped/UERJ. Doutorado em Educação Universidade Federal Fluminense. E-mail: mrvcaetano@gmail.com / ORCID: https://orcid.org/0000-0002-4128$\underline{8229}$.

${ }^{4}$ Universidade Estadual da Paraíba (UEPB). Doutorado em Educação - Universidade do Estado do Rio de Janeiro (UERJ) - Brasil. E-mail: emailsdapaula@gmail.com. 


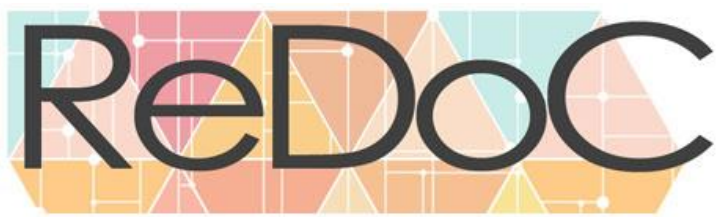

\section{Revista Docência e Cibercultura}

Hemisphere, since Connell, at the time, was publicizing her book Southern Theory: The Global Dynamics of Knowledge in Social Science. The theoretical possibilities of the South by the South were discussed, the role of the school in the introduction of the themes on the genre order, and finally the authors' reflections on their own questions about the author's work are presented.

KEYWORDS: Education, Equality, Masculinity, Gender, Etnographic Assessment

\section{RESUMEN}

Una conversa con Raewyn Connell tener empezar por su carrera académica del libro Haciendo la Diferencia: escuelas, las familias y la división social (1982), cuya publicación en portugués ampliado el interés de los investigadores en la educación, los estudios de género. Dada la amplitud de la producción de la autora en esta línea de estudios la conversación continúa con indagaciones sobre la importancia para la escuela en lidiar con ese tema, así como su interconexión con los estudios sobre masculinidades y sus teorizaciones internacionales y más particularmente en el hemisferio sur, ya que Connell, en la época estaba divulgando su libro Southern Theory: The Global Dynamics of Knowledge in Social Science. Se discutió las posibilidades teóricas del Sur por el Sur, el papel de la escuela en la introducción de los temas sobre las ordenaciones de género y finalmente se presentan reflexiones de los autores sobre sus propios cuestionamientos a cerca de la obra de la autora.

PALABRAS CLAVE: Educación, Igualdad, Masculinidad, Género, Evaluación Etnografía.

Raewyn Connell é uma pesquisadora conhecida mundialmente por sua extensa produção sobre os estudos de gênero, masculinidade(s) e sexualidade(s). Entretanto, com o livro Making the Difference: Schools, Families and Social Division, publicação coletiva de Raewyn Connell, Dean Ashenden, Sandra Kessler e Gary Dowsett, em 1982, surge o nosso interesse pelo trabalho de Connell, e, é neste contexto que se deu a conversa entre ela e os(as) autores(as) deste texto.

O livro, publicado no Brasil sob o título, Estabelecendo Diferenças: escolas, famílias e divisão social, em 1995, baseia-se em uma pesquisa etnográfica sobre as escolas e as moradias de pessoas ricas e poderosas e das assalariadas. O estudo etnográfico permitiu que crianças, responsáveis e docentes falassem sobre eles próprios. Elas desenvolveram: novas maneiras de entender as desigualdades educacionais; de como funcionavam os sistemas de classe e de gênero, e das expectativas sociais sobre as escolas. Neste sentido, as questões de pesquisa trataram as igualdades de oportunidades, coeducação e o currículo significativo de forma simples, mas incisivas. O livro abordou tanto a política educacional, a nível de sistema, como a experiência do dia a dia das crianças e de docentes, assim como; dos problemas de escolarização e da produção de relações de classe e de gênero. Essa combinação inovadora de teoria, pesquisa e política envolveu e instigou o(a)s leitor(a)s o que tornou o texto relevante em 


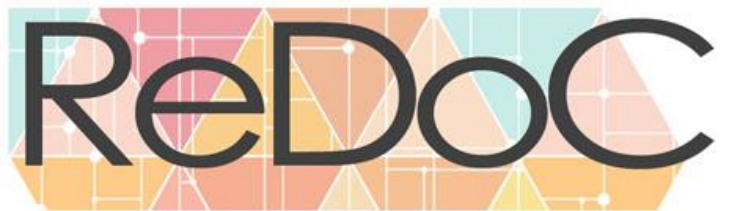

Revista Docência e Cibercultura

termos metodológicos e temáticos. Passado algumas décadas desde o lançamento do livro original, ele permanece no rol das referências mais importantes na área de Educação, na Austrália, no Brasil e em várias partes do mundo. Coloca de modo peculiar como as relações e ordenações de gênero têm um papel importante na organização pedagógica, no currículo e nas práticas da escola.

A conversa entre Raewyn, Carmen e Marcio se deu na Faculdade de Educação da Universidade do Estado do Rio de Janeiro em 13 de abril de 2015, as questões foram previamente preparadas e enviadas a autora com um dia de antecedência. Raewyn havia finalizado uma conferência ${ }^{5}$ e, portanto, estava cansada da maratona de fuso horário de 13 horas e três dias de conferências. Foi uma gentileza enorme da parte dela encontrar fôlego para mais duas horas de conversa.

Apresentar-se-á a seguir as questões formuladas a título de conhecimento e pertinência das respostas, mas a conversa será editada em acordo com as falas como elas se apresentaram a partir da linearidade da conversa.

Questões:

1. Raewyn você é conhecida internacionalmente por suas pesquisas e produções no campo dos Estudos das Masculinidades e esses estudos se interconectam substancialmente os conhecidos Estudos de Gênero. Entretanto, seu trabalho também tem forte correlação com a Educação. Você poderia nos falar sobre seu percurso profissional e intelectual e de como suas pesquisas nos mais variados temas, repercutiram na área da educação?

2. No campo legislativo na educação brasileira é garantido um currículo diversificado frente a nossa pluralidade cultural. Porém, as avaliações estatizadas nacionais executadas pelo Governo Federal orientam os conhecimentos que devem ser universalizados na escola e esses são fortemente atravessados pela lógica global

\footnotetext{
${ }^{5}$ A conferência intitulada Embodiment [encorporação] das mulheres transexuais: gênero, medicina e política, foi ministrada na Faculdade de Psicologia da UERJ por Raewyn Connel, no dia 13/04, como o patrocínio do Centro Latino-Americano em Sexualidade e Direitos Humanos (CLAM) e do Laboratório Integrado em Diversidade Sexual e de Gênero, Políticas e Direitos (LIDIS/UERJ)
} 
europeia. Você poderia falar um pouco sobre os modos como a colonialidade opera nas escolas?

3. Com a velocidade das mudanças ocorridas no âmbito do acesso à informação no contexto global e a constante desvalorização docente e da escola em relação ao seu papel formador, você continua a pensar que a função da escola é proporcionar as pessoas o conhecimento e que o processo educacional é um processo de libertação como você afirmou no seu livro Making the difference (Connell, at. al., 1982)?

4. No Brasil, no geral, existe a predominância da utilização das teorias do mundo ocidental nortista e isso se faz sentir na produção de pesquisas no campo da educação, o que não se diferencia no cenário metodológico. Como você analisa a possibilidade de maior circulação e reconhecimento pelo sul da produção do sul?

5. Considerando sua importância intelectual internacional, rompendo inclusive com a colonialidade do Norte e ultrapassando as fronteiras australianas, o que você aconselharia aos/às jovens pesquisadores/as para que esses/as tenham o reconhecimento de suas produções?

6. Para algumas pessoas, a pedagogia enquanto campo de produção do conhecimento é vista como algo secundário dado suas dimensões empíricas, com a forte presença da subjetividade dos sujeitos envolvidos na produção do conhecimento e a supervalorização da teoria e do abstrato. Você poderia comentar sobre as dimensões subjetivas e empíricas para a produção do conhecimento?

7. Você tem sido a precursora dos Estudos de Gênero na perspectiva do sul. Poderia falar sobre as inovações dessa perspectiva e o quanto isso poderá incidir no campo de produção de conhecimento na Educação?

8. Quando você lançou o livro Masculinities (Connell, 1995) vivíamos, no geral, a ideia de um ethos unificado em torno da masculinidade e seu trabalho teve grande impacto porque trouxe a ideia da multiplicidade masculina. Paralelo ao seu livro, o mundo viveu o reconhecimento, em maior ou menor grau, dos direitos identitários e/ou cidadãos da população de lésbica, gay, bissexual, travesti e transexual (LGBT) e a crítica feminista a hegemonia masculina. Como você analisa o reconhecimento e os direitos civis da

\begin{tabular}{|l|l|l|l|l|l|l|} 
(C) Redoc & Rio de Janeiro & v. 3 & n.1 & p. 201 & Jan/Abr. 2019 & e-ISSN 2594-9004
\end{tabular}




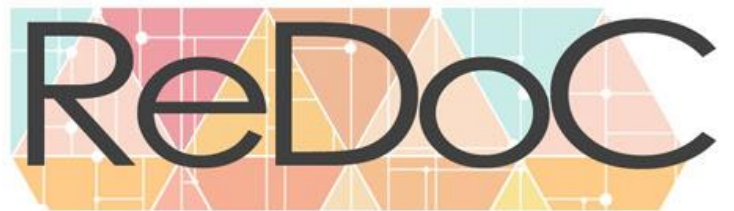

\section{Revista Docência e Cibercultura}

população LGBT e o protagonismo das mulheres na educação nesses 20 anos após o lançamento de Masculinities (idem)?

9. Quais as contribuições que a Teoria Queer e os Estudos Pós-coloniais teriam para a educação?

\section{Conversa.}

Carmen: Você quer ver as perguntas novamente?

Raewyn: Talvez.

Carmen: Posso explicar, se você desejar! A ideia principal Raewyn, é publicar essa conversa com você no contexto da educação e não focar exclusivamente nos estudos de gênero. Raewyn: Então me fale sobre quem é o público para o qual vocês querem escrever?

Carmen: O público é formado por pesquisadores(as) em educação interessados(as) em estudos sobre família, gênero e educação. Gostaríamos de ouvir sobre você. Quando falamos sobre você, você sabe! desperta sempre o interesse dos(as) leitores(as) sobre os estudos de gênero e masculinidade. Aqui (Brasil), como você falou na sua conferência, o interesse maior é em torno do seu trabalho sobre masculinidades. Gostaríamos de ouvir sobre a conexão entre o seu trabalho anterior e os de agora. Agora você está promovendo seu livro Southern Theory: The Global Dynamics of Knowledge in Social Science (Connell, 2007), e as pessoas querem saber sua opinião sobre o que fazer com a sua teoria? Como ela que está conectada a educação. Então, nós preparamos essas perguntas, bem, a primeira é sobre a sua trajetória profissional, o reconhecimento internacional do seu trabalho e também pelo um forte impacto que ele tem no campo da educação, especialmente os seus trabalhos iniciais. Você poderia nos contar um pouco sobre essa trajetória intelectual no campo da educação?

Raewyn: Bem, eu acho que vou por parte na questão, é que eu comecei na educação, eu suponho, como um praticante, antes de ser uma pesquisadora da educação, ou ao mesmo tempo, porque eu estava envolvida em um movimento para reformar as universidades que saíram do New Left [Nova Esquerda] na década de 1960, quando eu era uma estudante de pós-graduação. Nós desenvolvemos uma crítica à universidade, à pedagogia e aos currículos. Não foi apenas uma crítica, mas tentou-se criar algo alternativo. E assim, em Sydney, eu estava envolvida na criação de algo chamado Free University [universidade livre], que era uma tentativa de criar 


\section{Revista Docência e Cibercultura}

um sistema central de ensino superior radical que funcionou e durou cerca de três anos. Não tinha permanência como muitos projetos da New Left [risos], mas criava uma espécie de modelo de educação superior onde não havia distinção entre docentes e estudantes, onde a base eram grupos de pesquisa self-corrected [autocorrigidos] que abordavam problemas de tal importância que as principais universidades ignoravam: questões de violência, classe, poder, indigenismo, questões aborígines, estratégias de movimentos sociais. Então, isso continuou na minha carreira como professora universitária mais tarde, onde eu estava continuamente envolvida na tentativa de desenvolver uma pedagogia mais democrática na universidade. $\mathrm{E}$ novos currículos em áreas como gênero e análise cultural eram praticados. Então sempre houve um lado de prática no que eu estava tentando fazer na educação. Eu me tornei uma pesquisadora educacional através do meu doutorado sobre a consciência política das crianças e usei uma abordagem no estilo Piaget para o desenvolvimento do pensamento das crianças sobre o desenvolvimento da sociedade e questões políticas. Assim, minha primeira publicação em um periódico educacional foi desse material que se debateu questões sobre se as escolas estavam engajadas em propaganda educacional ao lidar com o governo e a política. E, parte dessa pesquisa foi sobre o entendimento das crianças sobre classe social e desigualdade, então eu publiquei coisas sobre a consciência de classe das crianças. Mas depois, me envolvi em um estudo com adolescentes, em Sydney. Era uma espécie de pesquisa, de amplo espectro, sobre a adolescência e eu era parte de uma equipe, cuja maioria estava no Departamento de Educação. E publicamos um livro chamado 2 to 20: Studies of City Youth" (Connell, at al., 1975) que era basicamente um amplo estudo da vida adolescente em Sydney, no final dos anos 60 e início dos anos 70. E, que tinha muitos dados sobre retenção educacional, diferenças sociais no desenvolvimento e desigualdades de classe na educação. Escrevi artigos sobre isso. Foi também quando minha primeira pesquisa sobre gênero na educação foi feita porque escrevi um artigo sobre os padrões de diferença sexual que emergiram nesta pesquisa.

Carmen: Então, lá havia espaço para isso. Para esse tipo de debate, aqui ainda não! Raewyn: E então, o neoliberalismo veio com sua visão estreita sobre cultura e com o estresse na competição, da vigilância e da quantificação. E começou a impor um regime de testes muito mais rígido do que antes e mais difundido. A questão central de antemão só tinha sido o currículo escolar, mas agora temos testes padronizados no ensino primário e no ensino médio. 


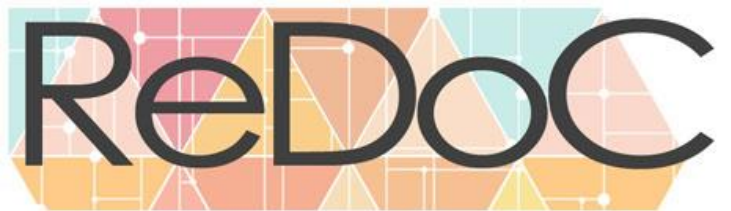

\section{Revista Docência e Cibercultura}

Carmen: No começo, como isso funcionava? Aqui, vou dar um exemplo, os(as) professores(as) estão treinando os estudantes para fazer os testes.

Raewyn: Claro! Eles sempre têm sim.

Carmen: Então, foi o mesmo lá?

Raewyn: Sim, sempre! Qualquer professor com a cabeça mais estreita vai ensinar a fazer o teste. Se for um teste de alto risco, que afeta o futuro da criança ou da escola, é claro que eles vão treiná-las para fazer o teste. Todo mundo sabe que é assim! Exceto os formuladores de políticas que provavelmente sabem disso e não se importam. Então, sim, fico furiosa com isso! É um processo profundamente destrutivo e distorce a educação e cria uma enorme ansiedade nas crianças pequenas. Ele incorpora a competitividade individual como a estrutura principal da escola e cria muito mais vigilância dos professores, porque eles agora medem a eficácia do professor por meio desses testes. Esse foi, de fato, um dos principais argumentos para trazêlos, uma vez que eles achavam que seriam capazes de dizer quais eram as escolas eficazes e quais eram os professores eficazes, medindo seus resultados.

Carmen: Eles estão até dando bônus para os professores.

Raewyn Connell: Sim. Então, eles estão trazendo de volta o pagamento pelos resultados que tivemos há 150 anos ou 200 anos atrás. E foi abandonado porque teve efeitos ruins sobre a educação. Então, estamos voltando há 100 anos ou mais. É horrível! Mas como agora existe um monopólio neoliberal nos meios de comunicação de massa, é muito difícil contestar isso. Agora temos um padrão similar de testes centralizados e a parte mais desagradável disso foi quando o governo nacional criou um site chamado minha escola - não nossas escolas - mas minha escola, e começou a colocar os resultados dos testes no site para que todos pudessem forçar as escolas a competirem umas com as outras.

Carmen: É o mesmo aqui.

Raewyn: Isso é nojento! E isso foi feito por um governo trabalhista, sabe?

Carmen: Isso foi consolidado pelo governo do PT (Partido do Trabalhadores) aqui também. 


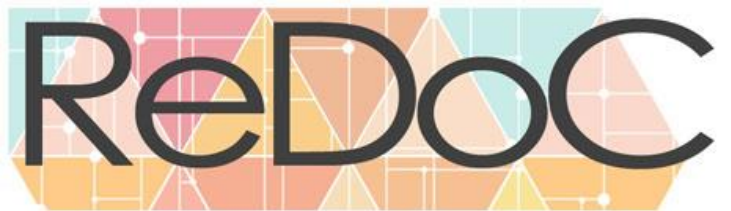

Revista Docência e Cibercultura

Raewyn: Então, muito disso vem da OCDE (Organização para a Cooperação e Desenvolvimento Econômico), que se tornou um banco de pensamento neoliberal que começou a controlar a política educacional.

Carmen: Mas, como você sabe essa organização teve inicio com os países Europeus, pois a América do Norte não está tão interessada nisso (na avaliação comparativa internacional). Raewyn: Bem, eles tentaram impor isso nos Estados Unidos como o ato intitulado - No Child Left Behind [Nenhuma Criança Deixada para Trás] ${ }^{6}$ que envolveu testes de responsabilidade dos professores e da escola através de testes. E esse era um governo de direita (Partido Republicano). Sim, é bem desanimador. Além disso, os testes não são muito bons. Eles não são realmente boas ferramentas educacionais.

Carmen: Sim! A ideia é que recebamos esse tipo de comparação de modo acrítico. Você compara o Brasil com outros países e sempre nos faz parecer mal. Pois, você pode imaginar países de baixa densidade demográfica comparados ao Brasil. É impossível comparar!

Raewyn: Mas, produz manchetes na mídia. E coisas para os políticos dizerem.

Carmen: A próxima pergunta é sobre a sua produção na educação, o livro que estávamos falando antes - Making the Difference (Connell, 1982). Você continua a pensar que a função da escola é prover o conhecimento aos alunos, mesmo com a velocidade das mudanças, o alcance de acesso à informação no contexto global, as avaliações constantes, os baixos salários dos professores? Estamos falando do lugar particular da escola nesse contexto, onde você pode obter informações em qualquer lugar diferente da escola. Então, você ainda acredita que a educação é um processo de libertação?

\footnotetext{
${ }^{6}$ A Lei No Child Left Behind (NCLB) nenhuma criança deixada para trás - foi uma Lei do Congresso dos EUA em 2002 na gestão do Presidente George W. Bush, que autorizou a Lei de Educação Elementar e Secundária a incluiu disposições aplicáveis a estudantes desfavorecidos com a intenção padronizar os programas de ensino e os testes na escolas (U.S. Department of Education, 2002).
} 


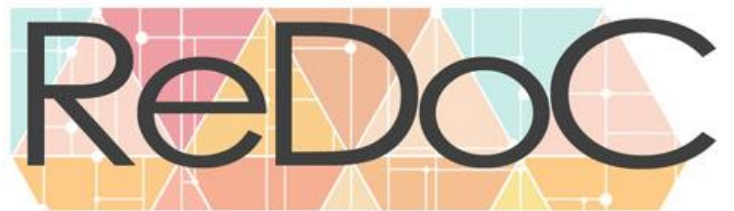

\section{Revista Docência e Cibercultura}

Raewyn: Hum, sim, acho que sim. Primeiro de tudo, muito do que você obtém na Internet não é conhecimento. É apenas fantasia, propaganda e distorção.

Carmen: Você acha que é apenas propaganda?

Raewyn: Não, eu não acho que é apenas propaganda, mas há muita propaganda lá. E conteúdo manipulativo, propaganda, produção de relações públicas, desde que grandes quantidades de conteúdo na Internet são comercialmente produzidas e reproduzidas, para ganho econômico, com todas as distorções que vêm com isso. É uma loucura! A televisão foi originalmente concebida como um meio educacional e veja o que aconteceu com isso, com todo o conteúdo indesejado e a desinformação veiculada pela televisão. O mesmo ocorre na Internet. Desde que a Internet foi originalmente concebida para fins militares e não para fins educacionais. Claramente, tem possibilidades educacionais, mas elas são inundadas pela comercialização e pelas distorções nela. Então, eu não acho que a escola tenha sido deslocada como fonte de conhecimento. Mas nesse mar de comunicações eletrônicas, é mais difícil para as escolas prender a atenção dos jovens à medida que passam cada vez mais tempo no mundo on-line. A escola tem que se adaptar a isso e encontrar maneiras de ajudar os jovens a navegar e criticar em um tipo diferente de ambiente de mídia. Eu acho que isso é uma responsabilidade das escolas, certamente. Penso na educação, na educação formal, ainda como um grande complexo institucional na maioria das sociedades e, como instituição, é um veículo de controle por interesses comerciais e por governos autoritários e até mesmo por governos supostamente democráticos. Portanto, o currículo está sempre sujeito a tentativas de controle. Mas também acho que as instituições de educação formal têm possibilidade educacional. E a chave para isso, absolutamente, é a força de trabalho docente. As possibilidades humanas dos professores para fazerem coisas educacionais dentro e fora das salas de aula com as crianças, criando oportunidades para as crianças se educarem, o que eu acho que é uma parte muito importante da educação, no nível universitário também.

Carmen: Então, para você a escola continua, não vai acabar?

Raewyn: Desculpe! Eu não acho que as escolas perderam suas funções, não! Também não acho que as universidades perderam sua função, embora existam agora MOOCs - Massive Open Online Courses e material online do MIT - Massachusetts Institute of Technology. A interação real em um campus universitário é realmente importante para o ensino superior e eu também 


\section{Revista Docência e Cibercultura}

acho que é um grande problema quando a função de produzir conhecimento é institucionalmente separada da função de educar e circular o conhecimento que é, naturalmente, entendido aqui quando a pesquisa é realizada em institutos de pesquisa em que o pessoal de pesquisa das universidades é separado do seu corpo docente, uma tendência agora. Ou ainda quando a pesquisa está localizada em corporações, que não têm nenhum interesse em educação, porque seu interesse real é manipular o público para obter vantagem comercial e lucrativa. Temos que pensar a escola como uma instituição de ensino e de pesquisa. Ela é uma instituição educacional e essas funções se juntam. É um local de articulação entre grupos de pessoas com diferentes tipos de recursos educacionais e isso pode produzir um significativo desnível nos testes. E isso, obviamente, é ignorado pela agenda neoliberal e pelo regime de testes padronizados.

Carmen: Como se pode evitar ser tomado pela rede? Como você poderia nos aconselhar a fazer algo sobre isso e a escola não ser consumida por recursos de "ensinos líquidos"?

Raewyn: Bem! Parte disso envolve luta nas novas mídias. Então, a contestação na rede, que eu sei pouco. Eu tenho 71 anos de idade. Mas eu não tenho muitas habilidades líquidas. Então, você precisa conversar com outras pessoas sobre isso [risos]; mas esse é um dos locais de luta. Acho que as organizações de professores e a 'indústria' nos setores de educação são importantes, por isso sou uma sindicalista ativa. Na verdade, conecto as possibilidades da educação com a capacidade das organizações de professores de proteger a autonomia da força de trabalho docente. O gerenciamento neoliberal é muito mais intrusivo do que o gerenciamento burocrático, devido a todos esses mecanismos de controle: gerenciamento de desempenho, prestação de contas, relatórios, o modelo on-line para cursos. Então, quanto mais isso for contestado, melhor! Não pode ser contestado em um nível individual. Ele pode ser subvertido um pouco, mas não pode ser contestado sem a força de uma ação coletiva. As discussões mais interessantes e importantes sobre o ensino superior que aconteceram na Austrália agora, estão acontecendo no sindicato nacional de educação superior, não no jornal, não no governo, não entre os vice-reitores, mas na verdade é no sindicato onde as melhores discussões educacionais estão acontecendo. Isso é parte disso, eu acho. Uma parte fundamental da contestação à reforma é a relação do professor com os alunos. Estamos fundamentalmente tentando fazer com que a universidade e a escola funcionem no interesse dos alunos. Essa é a base, são os fundamentos éticos nos quais testamos o regime de testes e o gerenciamento neoliberal. Essas coisas estão 


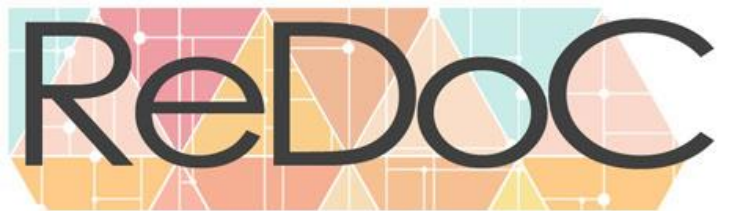

Revista Docência e Cibercultura

conduzindo o processo educacional para os alunos. Portanto, ganhar o apoio dos estudantes no nível de universalidade e mostrar qualidade na educação é realmente do interesse das pessoas nas escolas. Essa é uma dimensão importante de luta.

Carmen: Estamos chegando ao final, você parece cansada, mas você pode responder outra questão?

Raewyn: Claro, tudo bem! Me dê mais cinco e eu farei algo com elas (risos). Marcio: Muito obrigada eu aprecio sua generosidade.

Raewyn: Me desculpe por isso, eu estou viajando de avião por uma distância muito longa.

Marcio: Eu entendo, também viajo por períodos longos, mas já me acostumei. Mas realmente aprecio essa oportunidade. Gostaria que você falasse quais são as contribuições da Teoria Queer e dos Estudos de Gênero transcolonial para a educação?

Raewyn: Existe uma edição especial da Revista Discurso ${ }^{7}$ sobre isso, sobre Estudos Queer em educação que você pode achar interessante. Eu não sou uma entusiasta da Teoria Queer. Eu tenho críticas a elas.

Marcio: Deixe-me ir por outro caminho, talvez, seja um pouco menos complicado e mais prazeroso para você. Quando você lançou o seu livro Masculinities (Connell, 1995), esse trabalho teve grande impacto porque trouxe a ideia de multiplicidades sobre a masculinidade. Paralelamente ao seu livro, no mundo ocidental sobretudo, vivemos vários outros fatores: o reconhecimento político da população lésbica, gay, bissexual e trans (LGBT) e a severa crítica feminista à hegemonia masculina. Como você analisa o reconhecimento e a ampliação dos direitos civis das pessoas LGBT e o empoderamento das mulheres na educação, nesses 20 anos após o livro Masculininities?

Raewyn: Em primeiro lugar, eu diria que sou muito crítica ao conceito de pessoas LGBT. Eu acho que é um conceito enganoso, é como uma coleção de maçãs e laranjas. Você está lidando com coisas radicalmente diferentes e juntando-as. Não tem ajudado a criar um pensamento claro ou uma boa política. Então, como eu estava dizendo na minha conferência, esse conceito ajudou a circular a ideia de que tudo isso é sobre identidade e liberdade de expressão ou sobre

${ }^{7}$ Não conseguimos identificar na revista citada pela autora a edição especial mencionada.

\begin{tabular}{|l|l|l|l|l|l|l} 
(C) Redoc & Rio de Janeiro & v. 3 & n.1 & p. 208 & Jan/Abr. 2019 & e-ISSN 2594-9004
\end{tabular}




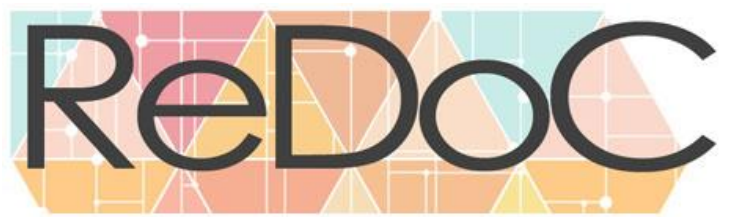

\section{Revista Docência e Cibercultura}

nossa identidade e os direitos humanos para expressar diferentes identidades. E, deste modo não se entende o que é a transição de gênero ou a construção do gênero. E define uma minoria sexual como um grupo que não é uma minoria sexual. Eu não acho que conceitos confusos sejam educacionalmente úteis.

Marcio: Então, introduzir as políticas LGBT na agenda educacional não seria uma boa ideia?

Raewyn: Não! Esse conceito, eu acho, não é uma coisa boa para se ter na agenda educacional [...]. Acho importante ter o reconhecimento no currículo do significado humano das relações de gênero e das relações sexuais de gênero, de modo que o currículo precisa do feminismo para não ser um currículo patriarcal e heteronormativo. Isso auxilia a compreensão escolar dos modos que produziram as desigualdades de gênero e sexuais na sociedade. Quero dizer, está muito longe de ser completo e certamente houve reações e retrocessos em algumas partes do mundo. Então, agora na Rússia é ilegal ensinar sobre a homossexualidade em escolas onde as crianças precisam saber sobre a homossexualidade. Hum, então isso é profundamente antieducativo. Em outras partes do mundo, mesmo não sendo ilegal, é socialmente difícil o debate porque os professores estariam sujeitos ao assédio, às críticas e objeção de pais. Temos, nos últimos 20 anos, não em todos os lugares, não de modo uniforme, em linhas gerais, um período de reação de gênero que teve poderosos movimentos e mobilizações antifeministas e de construção de novos patriarcados, como o russo ou o reforço do poder patriarcal na China sob um regime supostamente igualitário e de corporações transnacionais mediadas pelas agendas econômicas globalizadas. Tudo isso é administrado por grupos de homens com uma cultura de gestão de ocupação fortemente masculinizada. Então, nós realmente não estivemos em um momento histórico muito progressivo nesses 20 anos. E embora a pesquisa sobre masculinidades certamente tenha se expandido e se tornado mais sofisticada, interessante e internacional, o campo mais global de conhecimento ainda apresenta recursos importantes para o currículo.

Marcio: Seu trabalho traz a subjetividade das pessoas que estão sendo entrevistadas. Essa é uma lição importante que aprendi com você, [...] quando se desconsidera a voz das pessoas, a humanidade das pessoas... [Raewyn interrompe]

Raewyn: Não apenas suas subjetividades, mas, de maneira central, suas práticas sociais, o que elas realmente fazem, a criatividade de sua vida cotidiana. Como argumentei em meu livro 


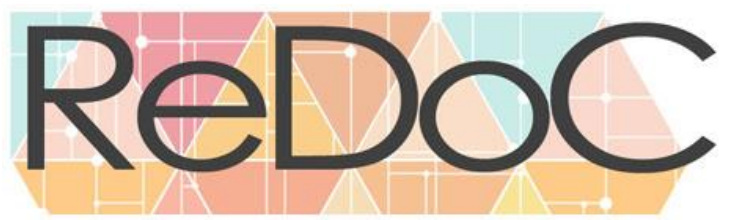

\section{Revista Docência e Cibercultura}

Schools and Social Justice [Escolas e Justiça Social] (Connell, 1993) uma parte fundamental da justiça social é a justiça nos currículos. Currículos que, de várias formas, representam o interesse dos grupos mais poderosos e não do menos privilegiados. Esta é a história usual dos currículos. Assim, parte disso é a capacidade do currículo incluir as vozes dos marginalizados, aqueles que são os menos poderosos em diferentes estruturas sociais.

Carmen: Nós temos muita sorte de ter você aqui e lamento exploramos ao máximo esse momento. Me desculpe por isso. Um dia importante para nós ter você aqui. Muito obrigado mesmo.

Raewyn: OK, espero que tenham algo de útil para a publicação.

Carmen: Certamente! Mais do que útil, muito obrigada, estamos muito gratos por disponibilizar esse tempo conosco, mesmo muito cansada.

\section{REFLEXÕES}

Após reconhecimento de suas pesquisas sobre as dinâmicas de classe publicadas em Ruling Class, Ruling Culture: Studies of Conflict, power and hegemony in Australian Life (Connell, 1977) e conexão entre os marcadores classe e gênero nas dinâmicas escolares in Making the Difference (Connell, 1982), Raewyn Connell desenvolveu uma teoria de gênero enquanto estrutura social expressa no livro Gender and Power: Society, the Person, and Sexual Politics (Connell, 1987) e publicou, em 1995, o livro Masculininities, ainda não traduzido para o português, este livro é constituído em torno do conceito de masculinidade hegemônica, certamente é uma das principais referências nas ciências humanas e sociais para os estudos sobre masculinidades. Este conceito teve como objetivo central a análise dos processos de hierarquização, normatização e, sobretudo, de marginalização das masculinidades subalternas.

A Nova Esquerda Australiana, a emancipação política de países colonizados e os movimentos de contracultura permitiram aos/às intelectuais da geração de Connell os sentimentos ousados necessários à contestação das instituições normatizadoras. A expansão do sistema universitário australiano dos anos 1940-1970 certamente deu à pesquisadora as bases institucionais para o desenvolvimento de suas pesquisas e com elas as críticas às desigualdades educacionais e sexuais que fragilizariam os muros que protegiam a masculinidade.

Vários fatores convergiram, na década de 1980, para a emergência do questionamento à masculinidade: o movimento pacifista criticava fortemente o militarismo, a masculinidade 


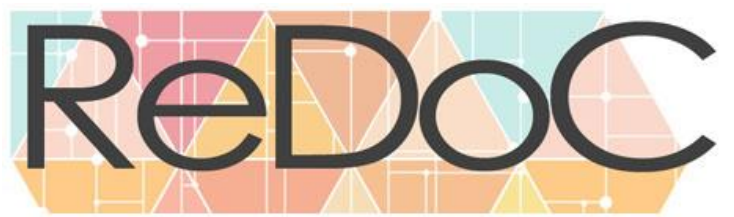

\section{Revista Docência e Cibercultura}

heterossexual foi fortemente problematizada pelos movimentos das chamadas minorias sexuais à medida que se desenvolvia a epidemia do $\mathrm{HIV} / \mathrm{AIDS}^{8}$. As ciências sociais e humanas colocaram em xeque a naturalidade das formas dominantes e dentro delas, a masculinidade hegemônica. Tudo isso ocorria em paralelo aos avanços feministas, mas também com os retrocessos neoliberais.

As políticas neoliberais, com suas práticas anti-participativas e anti-democráticas, não abandonaram o imperativo político do homem forte, autoritário, racional, eficiente e impiedoso. Existem relações concretas entre masculinidade e o neoliberalismo, sobretudo, por meio do modelo hegemônico de gestão empresarial. A globalização neoliberal inaugurou outras instituições e espaços sociais que se ampliaram em escala global por meio da internet, dos modelos de Estados promotores de segurança transnacionais, dos mercados e empresas multinacionais. Essas instituições são organizadas por sistemas de gênero geograficamente estendidas e altamente complexas.

Para Connell, as pesquisas sobre as masculinidades não são os únicos dispositivos para a análise da ordem neoliberal global, mas vai ajudar à compreensão do funcionamento de suas instituições capitalistas. Não obstante ao feito, Connell, em seu livro Southern Theory: The Global Dynamics of Knowledge in Social Science (Connell, 2007), propôs uma outra alternativa de produção de conhecimento para as Ciências Sociais e Humanas. Ao afirmar que a teoria do gênero, de fato, teve relações estabelecidas a partir da metrópole global: Europa e América do Norte, ela nos chama a atenção para o fato de que as sociedades que foram colonizadas têm sido forçadas a refletir e debater os efeitos da colonização independentemente da lógica dos colonos. A periferia global continuou a produzir conhecimentos em contrassenso a lógica econômica dominante de produção de saberes, isso ela o chamou de Teoria do Sul.

A permanente luta contra hegemônica da autora nas escolas se refletem no despertar global para os seus escritos. Nosso interesse em seu ponto de vista aqui descrito, se inserem na temática dos currículos escolares e da urgência dessas lutas no campo da educação. A pauta neoliberal que cerca a escola no momento atual, amplia os muros da escola pelo machismo, homofobia e outros com o injustificável apelo da dominação das politicas feministas e marxistas pela escola e universidades. $\mathrm{O}$ passo atrás descrito por Raewyn no início de sua fala, não se limitam aos testes macronacionais aplicados nas escolas de natureza macro politica e mercadológica, naturalizados pelo machismo tóxico,

\footnotetext{
${ }^{8}$ Human Immunodeficiency Viruses (HIV). Acquired Immunodeficiency Syndrome (AIDS)
} 


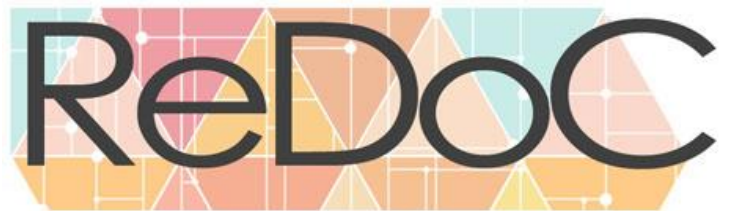

Revista Docência e Cibercultura

que se traduz no alarmante fenômeno do feminicídio e das agressões contra pessoas diferentes simplesmente por elas existirem.

Esses muros, não impedem a violência diuturna vivida pelas crianças e jovem nas escolas e fora dela, mas dificultam o diálogo entre professores e seus alunos e dos alunos e alunas entre si, sobre um universo cultural e social que habitam e sobre aspectos relacionados às sexualidades, masculinidades, feminilidades presentes em seu cotidiano.

Raewyn nos alerta, sobre o quão necessários se fazem os estudos de gênero no contexto da educação e dá destaque especial à dialógica entre os estudantes e suas relações socioculturais.

\section{Referências}

CONNELL, R. W. Southern Theory: The Global Dynamics of Knowledge in Social Science. Sydney, Allen \& Unwin Australia; Cambridge, Polity Press, 2007.

CONNELL, R.W. Gender and Power: Society, the Person, and Sexual Politics, California: Stanford University Press, 1987.

CONNELL, R.W. Ruling Class, Ruling Culture: Studies of Conflict, power and hegemony in Australian Life. Cambridge, UK: Cambridge University Press, 1977. 264p.

CONNELL, R.W. Schools and Social Justice (Our Schools), Philadelphia: Temple University Press, 1993. 140 p.

CONNELL, R.W. Masculinities. Cambridge, Polity Press; Sydney, Allen \& Unwin; Berkeley, University of California Press, 1995.

Connell, RW, DJ Ashenden, S Kessler and GW Dowsett. Making the Difference: Schools, Families and Social Division. Sydney, Allen \& Unwin, 1982. Tradução no Brasil [Estabelecendo a Diferença: Escolas, Famílias e Divisão Social, Porto Alegre, Artes Medicas, 1995].

CONNELL, W. F; STROOBANT, R. E; SINCLAIR, K. E; CONNELL R. W.; ROGERS.K. 2 to 20: Studies of City Youth. Sydney: Hicks Smith \& Sons, 1975.

U.S. Department of Education. No Child Left Behind Act of 2001, PUBLIC LAW 107-110JAN. 8. 107th Congress: Washington, DC. 2002 